\title{
Importância do co-cultivo com fibroblastos de camundongo 3T3 para estabelecer cultura de suspensão de células epiteliais do limbo humano
}

\author{
Importance of 373 feeder layer to establish epithelial cultures from cell \\ suspension obtained from corneo-scleral rims
}

\author{
Priscila Cardoso Cristovam ${ }^{1}$ \\ Maria Aparecida da Glória ${ }^{2}$ \\ Gustavo Barreto Melo ${ }^{3}$ \\ José Álvaro Pereira Gomes ${ }^{4}$
}

Trabalho realizado no Departamento de Oftalmologia da Universidade Federal de São Paulo - UNIFESP - São Paulo (SP) - Brasil.

${ }^{1}$ Biomédica do Centro Avançado de Superfície Ocular (CASO), Instituto da Visão da Universidade Federal de São Paulo - UNIFESP - São Paulo (SP) - Brasil.

2 Biomédica do Centro Avançado de Superfície Ocular (CASO), Instituto da Visão da UNIFESP - São Paulo (SP) - Brasil.

${ }^{3}$ Residente do Departamento de Oftalmologia da UNIFESP - São Paulo (SP) - Brasil.

${ }^{4}$ Doutor em Ciências e Professor afiliado do Departamento de Oftalmologia da UNIFESP - São Paulo (SP) Brasil.

Endereço para correspondência: José Alvaro P. Gomes Rua Sabará, 566/43 - São Paulo (SP) CEP 01239-010 E-mail: japgomes@uol.com.br

Estudo realizado com auxílio financeiro da FAPESP, $\mathrm{MCT} / \mathrm{CNPq}$, DECIT/MS e Fundo Setorial de Biotecnologia CT-Biotecnologia

Recebido para publicação em 11.02.2008

Última versão recebida em 12.06.2008

Aprovação em 13.06.2008

\begin{tabular}{|l|}
\hline RESUMO \\
\hline Objetivo: Avaliar a importância da presença de células 3T3 para estabe- \\
lecer cultura de suspensão de células epiteliais do limbo obtido de rimas \\
córneo-esclerais. Métodos: Rimas de diferentes doadores tiveram seus \\
estroma posterior e endotélio removidos (n=6). Cada rima foi dividida em \\
três segmentos iguais, que foram colocados em cultura em três diferentes \\
condições: um segmento foi colocado na placa de cultura com o lado \\
epitelial para cima (Grupo A). Os dois segmentos restantes foram tripsi- \\
nizados e a suspensão de células obtida foi cultivada com (Grupo B) ou \\
sem (Grupo C) células 3T3 irradiadas. As células foram mantidas em meio \\
de cultura "supplemental hormonal epithelial médium" (SHEM), a migra- \\
ção epitelial e a formação de clones nos grupos A, B e C foram avaliadas \\
pela microscopia de contraste de fase e por coloração pela rodamina B. Os \\
resultados foram comparados estatisticamente. Resultados: O crescimen- \\
to de células epiteliais foi observado em 4/6 rimas (Grupo A). Todas as \\
suspensões de células epiteliais que foram cultivadas com células 3T3 \\
(Grupo B) formaram clones. Nenhuma adesão ou formação de clones \\
verdadeiros (holo ou meroclones) foi observada na cultura de células que \\
foi cultivada sem 3T3 (Grupo C) (p=0,009). Conclusões: Suspensão de \\
células epiteliais límbicas obtidas de rimas córneo-esclerais no modelo \\
utilizado precisa ser cultivada com células 3T3 para formar clones e \\
estabelecer colônias epiteliais com perspectivas para uso terapêutico na \\
reconstrução da superfície ocular.
\end{tabular}

Descritores: Células epiteliais; Técnicas de cultura de células; Diferenciação celular; Células-tronco; Limbo da córnea

\section{INTRODUÇÃO}

A superfície ocular normal é composta por epitélio estratificado, altamente especializado, formado basicamente por dois tipos de células fenotipicamente diferentes: células epiteliais conjuntivais e células epiteliais corneais $^{(1-4)}$. As células epiteliais corneais são transparentes e dispostas mais homogeneamente do que as células epiteliais conjuntivais, o que as torna essenciais para a visão. Células epiteliais da córnea são derivadas de células tronco localizadas na camada basal do epitélio do limbo que é a junção anatômica entre a córnea e a conjuntiva ${ }^{(5)}$. Essas células são caracterizadas pela alta capacidade de auto-renovação e alto potencial proliferativo.

Doenças cicatrizantes da superfície ocular, tais como síndrome de Stevens-Johnson e penfigóide cicatricial ocular, podem ter o epitélio límbico 
completamente destruído. Neste caso, células do epitélio conjuntival invadem a superfície corneal vizinha acompanhadas de inflamação crônica e neovascularização, num processo denominado conjuntivalização, que quando alcança o eixo visual, pode afetar gravemente a acuidade visual ${ }^{(1)}$.

Várias tentativas foram feitas para estabelecer um tratamento cirúrgico eficiente para a deficiência límbica total ${ }^{(6)}$. Entre elas destacam-se o transplante de limbo ${ }^{(7)} \mathrm{com}$ ou sem membrana amniótica. Porém, tais técnicas apresentam limitações, principalmente nos casos de doador alógeno, já que podem estar sujeitas a processo de rejeição ou exaustão das células transplantadas.

A técnica ideal de reconstrução da superfície ocular seria aquela em que houvesse reposição autógena das células límbicas, sem a perda da maioria da população das células doadoras. A expansão ex vivo de células epiteliais corneais com subseqüente transferência para a superfície corneal no tratamento da deficiência límbica foi primeiramente descrita por alguns autores $^{(7)}$. Neste estudo, os autores utilizaram células límbicas em suspensão, tendo a fibrina como substrato para a expansão epitelial. Alguns autores demonstraram que células epiteliais límbicas humanas podem ser cultivadas sobre a superfície côncava de lentes de contato de colágeno e transportadas para superfície de córneas de coelhos com $50 \%$ de sucesso ${ }^{(8)}$. Vários autores já demonstraram que células progenitoras epiteliais podem ser obtidas a partir de biópsia do limbo de aproximadamente $2 \mathrm{~mm}^{2(8-9)}$ e, depois de expandidas ex vivo sobre a membrana amniótica, serem transplantadas para o olho acometido $^{(10)}$. Todas essas técnicas de transplante de células cultivadas ex vivo são promissoras, uma vez que diminuem o problema de tecido doador insuficiente e de rejeição (quando autológos). No entanto, possuem algumas dificuldades, pois não garantem que as células epiteliais transplantadas venham a repovoar a superfície ocular receptora no pós-operatório.

$\mathrm{O}$ uso de co-cultura com células de fibroblastos de camundongo 3T3 letalmente irradiadas (ou tratadas com mitomicina C) como camada nutriente (feeder layer) das culturas epiteliais tem sido preconizado como de fundamental importância para aumentar o crescimento, a sobrevivência e manter a característica de indiferenciação das células tronco de diferentes tecidos, incluindo medula óssea, cordão umbilical, fígado ${ }^{(1)}$ e bexiga ${ }^{(12)}$. Este sistema de co-cultura também tem sido empregado por autores que utilizam suspensão de células epiteliais límbicas ${ }^{(13)}$ ou de mucosa oral ${ }^{(14)}$ para reconstrução da superfície da córnea.

Este trabalho teve como objetivo avaliar a importância da presença de células fibroblastos 3T3 para estabelecer cultura de suspensão de células epiteliais do limbo cultivadas ex vivo. Com isso, intenciona-se padronizar esse tipo de técnica visando abrir novas perspectivas no tratamento da deficiência de limbo.

\section{MÉTODOS}

O projeto de pesquisa teve andamento após aprovação da comissão de ética da Universidade Federal de São Paulo.

\section{Cultivo e preparo de células fibroblastos $3 T 3$}

Células fibroblastos (NIH-3T3) foram preparadas para cocultura das células epiteliais da córnea. Inicialmente, culturas estabelecidas de NIH-3T3 foram cultivadas em meio DMEM suplementado com $10 \%$ de soro bovino fetal (SBF). Ao atingir confluência, essas células foram submetidas à irradiação (6000 rads) e plaqueadas na densidade de $2,2 \times 10^{4}$ células $/ \mathrm{cm}^{2} 24$ horas antes de receberem as células epiteliais da córnea.

\section{Obtenção, preparação e cultivo das células epiteliais límbicas}

O tecido límbico foi obtido a partir das rimas córneoesclerais remanescentes da trepanação de córneas previamente utilizadas em cirurgias de transplante de córnea.

Culturas primárias de epitélio corneal límbico humano foram obtidas de acordo com técnica descrita já por nós utilizada em trabalhos prévios ${ }^{(15-16)}$. Na câmara de fluxo laminar, foi feita a dissecção da metade posterior do estroma do resto da córnea. Dois a três explantes obtidos da mesma rima foram colocados com a face epitelial para cima em placa de cultura, constituindo o grupo A.

Os outros fragmentos foram incubados com $1 \mathrm{ml}$ de tripsina $1 \mathrm{~g} / \mathrm{ml}($ EDTA/PBS $0,02 \%)$ por 30 minutos a $37^{\circ} \mathrm{C}$ para isolar as células, seguindo técnica descrita previamente por alguns autores ${ }^{(7)}$. Os pedaços de rimas foram então removidos, a tripsina inativada e a suspensão de células centrifugadas a $1200 \mathrm{rpm}$ por 4 minutos. Este procedimento foi repetido por três vezes com os mesmos fragmentos de rima e as células obtidas foram cultivadas com (Grupo B) ou sem (Grupo C) células fibroblastos $3 \mathrm{~T} 3$ irradiadas. Um grupo contendo apenas fibroblastos $3 \mathrm{~T} 3$ foi constituído como controle negativo. As células foram mantidas em meio de cultura SHEM (sup-

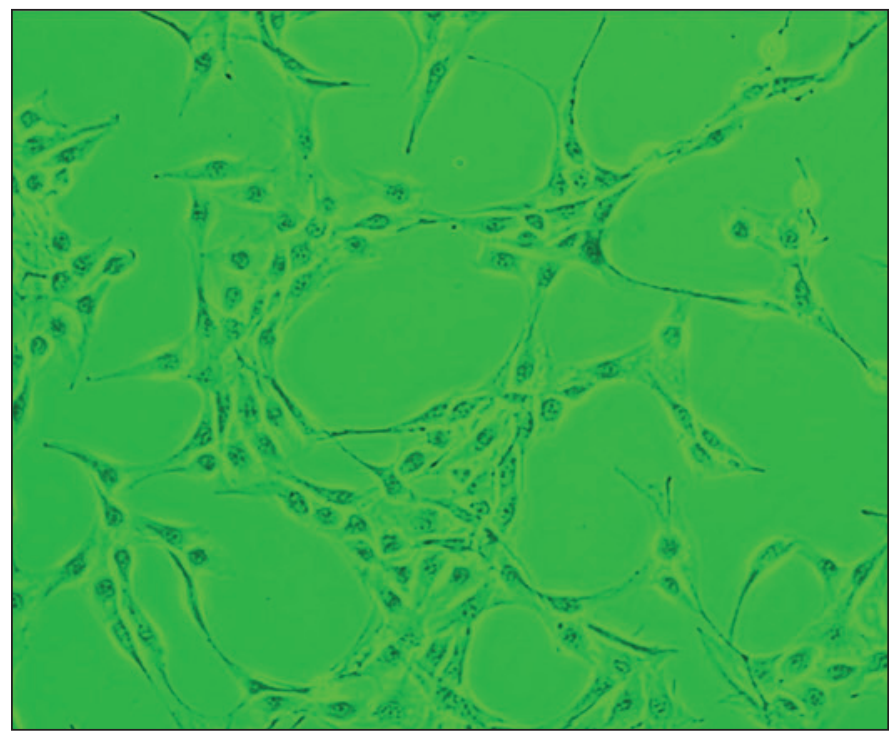

Figura 1 - Cultura de fibroblasto de camundongo 3Т3 logo após irradiação, antes de receber células epiteliais do limbo 
plemental hormonal epithelial medium), o qual consiste da combinação dos meios DMEM e HAM'S F12 (1:1 v/v), acrescido de $5 \mu \mathrm{g} / \mathrm{ml}$ insulina cristalina bovina (Sigma Aldrich, St. Louis, EUA), $30 \mathrm{ng} / \mathrm{ml}$ toxina colérica (Calbiochem, San Diego, CA), $2 \mathrm{ng} / \mathrm{ml}$ EGF (epithelial growth factor) (R\&D Systems, Inc. Minneapolis, EUA), 0,5\% DMSO (dimetilsulfóxido) (Sigma Aldrich, St. Louis, EUA), 0,5 $\mu \mathrm{g} / \mathrm{ml}$ hidrocortisona, $5 \mathrm{ng} / \mathrm{ml}$ selenato de sódio, $5 \mu \mathrm{g} / \mathrm{ml}$ apo-transferrina e $10 \%$ de SBF. Todos os reagentes foram obtidos da Invitrogen Corporation, Grand Island, NY, EUA, exceto aqueles indicados no texto. As culturas foram colocadas em incubadora a $37^{\circ} \mathrm{C}$ umidificada, $5 \% \mathrm{CO}_{2}$. O meio de cultura foi trocado duas vezes por semana, e os explantes foram deixados nas

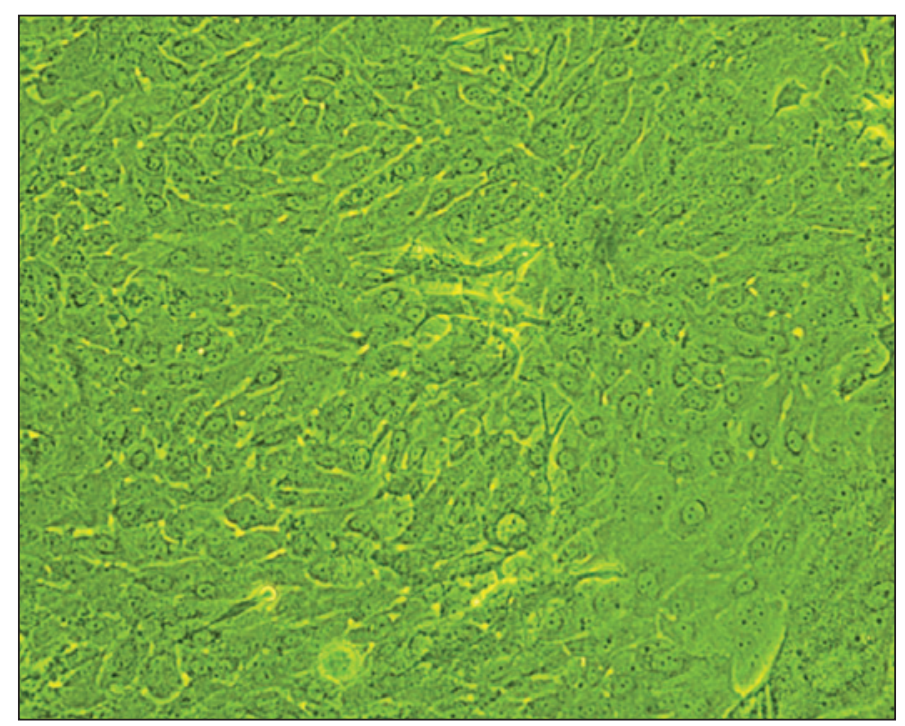

Figura 2 - Cultura do grupo A após confluência evidenciando epitélio compacto com características fenotípicas de epitélio corneano

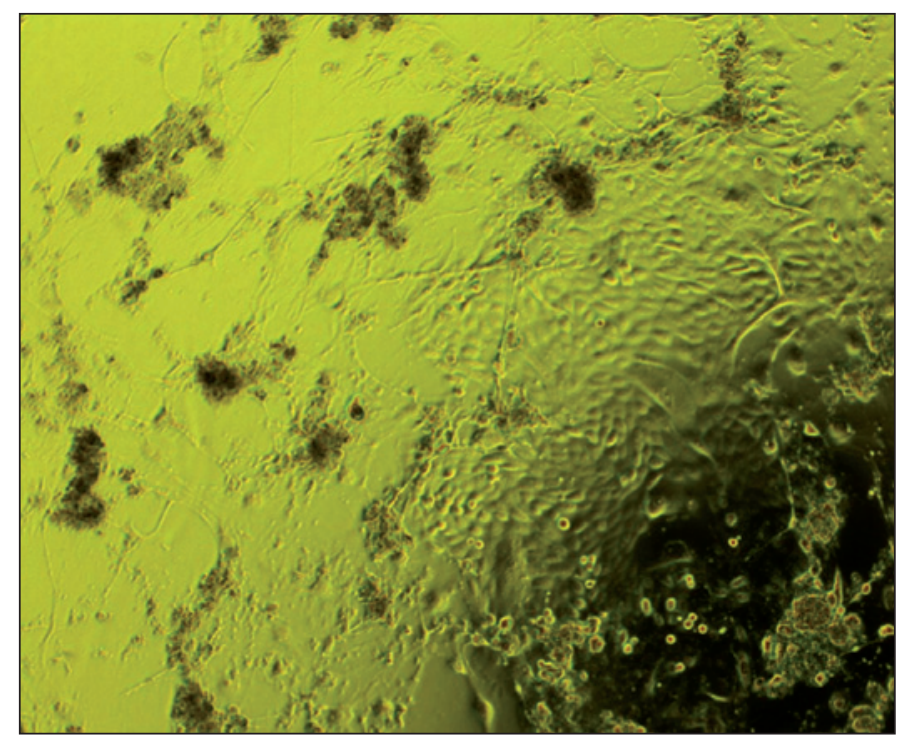

Figura 3 - Cultura do grupo B mostrando formação de clone de células epiteliais límbicas co-cultivadas com fibroblastos $3 \mathrm{~T} 3$ placas de cultura durante todo o tempo de incubação. Após 20 dias, o meio de cultura foi removido e as células foram fixadas e coradas com rodamina B (Sigma Aldrich, St. Louis, EUA). A migração epitelial e a formação de clones nos grupos A, B e C foram avaliadas pela microscopia de contraste de fase e pela coloração com rodamina $\mathrm{B}$.

\section{Caracterização fenotípica das células epiteliais}

Células das culturas epiteliais foram removidas ao final do experimento e foram colocadas nos compartimentos de um Cytospin (Shandon, Pittsburgh, PA EUA), centrifugadas a 1000 rpm por 10 minutos para preparação de lâminas contendo 5000 células cada, que foram secadas por 24 horas à

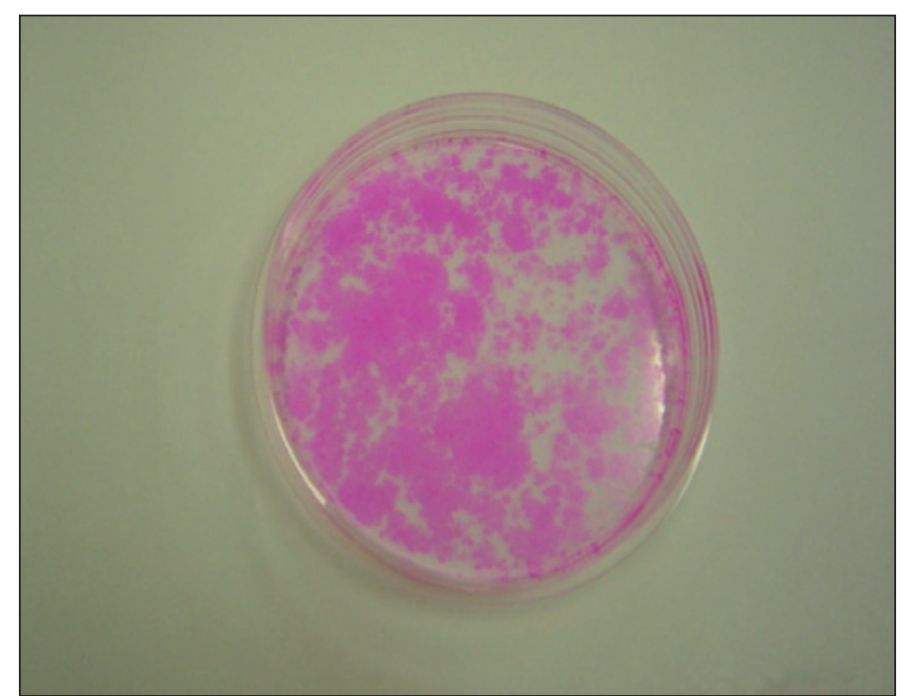

Figura 4 - Placa de cultura de células epiteliais límbicas co-cultivadas com fibroblastos 3T3 após fixação e coloração com rodamina demonstrando formação de múltiplos clones

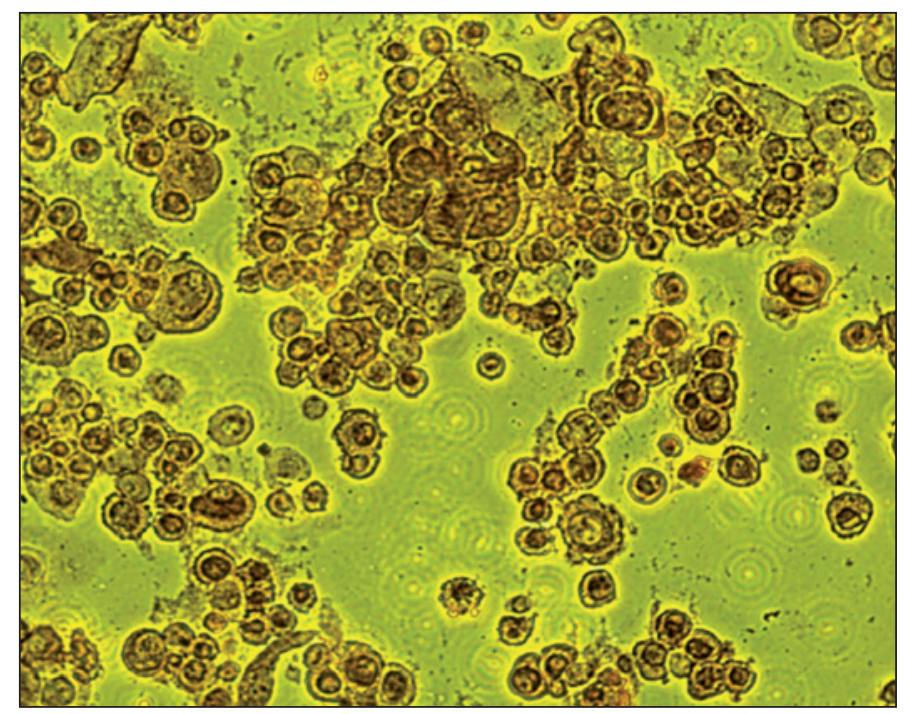

Figura 5 - Imunohistoquímica mostrando que as células epiteliais coram com anticorpo anti-citoqueratina epitelial 3 (AE-5) (microscopia de fase de contraste $\mathbf{x 1 0 0 )}$ 
temperatura ambiente. Em seguida, as células foram fixadas em acetona gelada por 10 minutos e incubadas com solução de bloqueio. Após 3 lavagens de 5 minutos cada com TBS (Tris Buffered Saline), as amostras foram incubadas com anticorpo monoclonal de camundongo AE-5 (queratina monoclonal anti-epitelial), (Chemicon International, Temécula, CA), específico para queratina epitelial $\mathrm{K} 3^{(15-16)}$. Os controles negativos receberam apenas diluente de anticorpo. Após 2 horas, foram realizadas 3 lavagens de 5 minutos cada com TBS, e em seguida as amostras foram incubadas com kit de amplificação LSAB (labeled streptavidin biotin) por 30 minutos cada, e as reações foram então reveladas com DAB (diamino-benzidina). Todos os reagentes para a realização de imunocitoquímica foram obtidos da DakoCytomation (Carpinteria, California, USA).

A proporção de células positivas em cada lâmina foi determinada pela análise de 200 células/lâmina, utilizando microscópio óptico no aumento x 100 .

\section{Análise dos clones}

As placas de cultura de todos os grupos foram observadas no $1^{\circ}, 3^{\circ}, 7^{\circ}, 14^{\circ}$ e $21^{\circ}$ dias, sob microscopia de contraste de fase, modelo Eclipse TS100 (Nikon, Japão), com aumento de 40 e 100 vezes. As imagens foram capturadas por uma câmara e digitalizadas para computador utilizando o programa Evolution LC Camara Kit (Media Cybernetics, Inc. EUA), avaliando-se a aderência das células à placa de cultivo, morfologia celular epitelial (forma arredondada não aderida ou poligonal, como originalmente é observada in vivo), multiplicação celular (pelo preenchimento de espaços vazios na placa e capacidade de formação de clones pela observação individualizada de uma célula e sua multiplicação por consecutivas mitoses).

\section{Análise estatística}

A comparação entre o crescimento das culturas/formação de clones entre os três grupos de estudo foi feita pelo teste $\mathrm{Q}$ de Cochran. As comparações pareadas $\mathrm{AxB}, \mathrm{AxC}$ e $\mathrm{BxC}$ foi feita pelo teste de McNemar. Neste trabalho, foi adotado o nível de significância de $5 \%(\mathrm{p}<0,05)$ e o sistema SPSS $^{\circledR}$ foi empregado para os cálculos estatísticos.

\section{RESULTADOS}

Seis rimas foram obtidas do centro cirúrgico do departamento de oftalmologia do Hospital São Paulo. Esses tecidos foram preservados em meio de preservação Optisol por 2-14 dias após a morte do doador. Idade do doador, tempo entre a morte e a preservação e tempo entre a morte e a cultura encontram-se discriminados na tabela 1 .

As células epiteliais em cultura foram avaliadas por microscópio de contraste de fase (Nikon, Japan). Apenas nos sistemas de cultura com explante (Grupo A) e suspensão de células epiteliais co-cultivadas com fibroblastos 3T3 (Grupo B) foram observados indícios de proliferação/migração celular com características epiteliais. Nas culturas obtidas do explante (grupo A), as células epiteliais migraram a partir dos fragmentos de rima nos estágios iniciais de crescimento 3-8 dias e atingiram confluência em 14-21 dias. Nas culturas de suspensão de células epiteliais co-cultivadas com fibroblastos 3T3 (Grupo B), pequenas colônias (clones) de células epiteliais começaram a ser observadas nos estágios iniciais de crescimento (3-6 dias), expandiram-se e atingiram confluência em 10-14 dias. A média de tempo de formação dos clones foi de 21 dias ( \pm 5 dias). A morfologia das culturas epiteliais obtidas a partir da suspensão celular apresentou aspecto mais compacto e uniforme do que as células obtidas do explante. Por outro lado, nas culturas de células epiteliais que foram cultivadas sem fibroblastos 3T3 (Grupo C), apenas duas culturas formaram clones pequenos, em pouca quantidade, que não mantiveram adesão após a coloração por rodamina, tendo sido considerados como negativos na análise estatística (Tabela 2).

Houve diferença estatisticamente significante entre os 3 grupos de estudo $(\mathrm{p}=0,009)$. Na comparação entre os grupos, diferença significativa foi encontrada entre os grupos $\mathrm{BxC}$ $(p=0,031)$. Não foram encontradas diferenças significativas entre os grupos $\mathrm{AxB}(\mathrm{p}=0,500)$ e $\mathrm{AxC}(\mathrm{p}=0,125)$.

\section{DISCUSSÃO}

Diferentes grupos vêm aprimorando técnicas de cultivo celular e expansão de células progenitoras epiteliais ex vivo

\begin{tabular}{|lccccc|}
\hline \multicolumn{5}{|c|}{$\begin{array}{c}\text { Tabela 1. Características das rimas córneo-esclerais em relação } \\
\text { ao doador, captação e preservação }\end{array}$} \\
Doador & Idade & Sexo & $\begin{array}{c}\text { Tempo morte/ } \\
\text { preservação }\end{array}$ & $\begin{array}{c}\text { Tempo morte/ } \\
\text { cultura }\end{array}$ \\
1 & 61 & $\mathrm{~F}$ & 8 horas & 7 dias \\
2 & 47 & $\mathrm{~F}$ & 2 horas & 9 dias \\
3 & 52 & $\mathrm{M}$ & 2 horas & 6 dias \\
4 & 24 & $\mathrm{M}$ & 12 horas & 11 dias \\
5 & 27 & $\mathrm{M}$ & 2 horas & 9 dias \\
6 & 49 & $\mathrm{~F}$ & 7 horas & 11 dias \\
Média \pm DP & $43,3 \pm 14,6$ & $3: 3$ & $5,5 \pm 4,1$ & $8,8 \pm 2,0$ \\
\hline
\end{tabular}

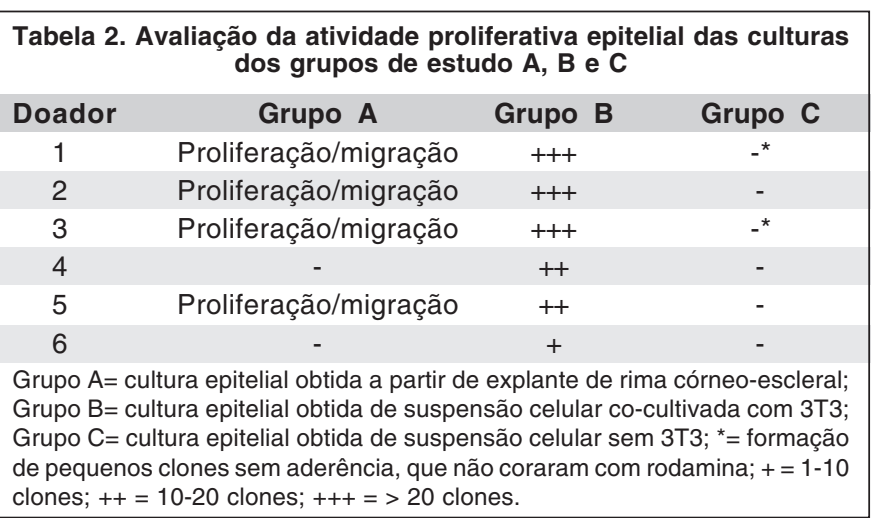


na tentativa de minimizar o dano na área do limbo doador e melhorar os resultados dos tratamentos já consagrados nos casos de deficiência límbica total ${ }^{(9-10,12-13)}$. Entre as técnicas descritas, podemos citar o cultivo de células epiteliais do limbo a partir de explantes de rima corneal ou o cultivo da suspensão de células epiteliais obtido da rima córneo-escleral após tratamento com tripsina/EDTA.

Cada método tem suas vantagens e desvantagens. A cultura dos explantes usualmente requer um pedaço do tecido menor do que o necessário para a suspensão de células e mantém o microambiente límbico, tido como importante na manutenção das características das células tronco epiteliais. Por outro lado, a cultura dos explantes está sujeita à contaminação por fibroblastos que migram do estroma e o rendimento de células geralmente é menor do que a cultura feita pela suspensão de células ${ }^{(14)}$. A digestão com tripsina também permite melhor avaliação quantitativa e qualitativa em relação à formação de clones epiteliais, o que representa um fator preditivo para a viabilidade da cultura ${ }^{(15-16)}$. Além disso, recentes trabalhos demonstraram que a marcação com $\mathrm{BrDu}^{(17)} \mathrm{e}$ com $\mathrm{p} 63^{(18)}$ foram mais evidentes em culturas obtidas pela suspensão de células do que em culturas de explantes.

Foi hipotetizado que a manutenção das características de indiferenciação e proliferação das células tronco do limbo é controlada por fatores extrínsecos e intrínsecos do seu microambiente local, chamado de nicho ${ }^{(19-22)}$. Esses fatores ambientais incluem a matriz extracelular do limbo, particularmente a membrana basal, interações célula-matriz e contato célula-célula. O estroma do limbo subjacente que contém células estromais e vasos sanguíneos deve também regular a função das células tronco pela liberação de fatores de crescimento ${ }^{(9,23-24)}$. Embora as características específicas de tais nichos não estejam completamente conhecidas, a manipulação de alguns dos seus componentes, incluindo proteínas da matriz extracelular e fatores de crescimento, já tem começado a ser explorada.

A importância de se usar o sistema de co-cultura com fibroblastos 3T3 deve-se à capacidade dessas células em sintetizar fibronectina, pequenas quantidades de colágeno tipo IV e laminina ${ }^{(25)}$. Além disso, as células de fibroblastos 3T3 secretam fatores de crescimento e proteínas de matriz extracelular ao meio de cultura ${ }^{(26)}$. Esses componentes produzidos pelos fibroblastos 3T3 parecem facilitar a adesão e crescimento dos queratinóticos, além de promover o efeito de mitógenos, como reportado em outras culturas ${ }^{(27)}$. Isto explica o efeito do meio condicionado pelas células 3T3 sobre o crescimento de queratinócitos ${ }^{(26)}$.

A análise dos tipos de clones ajuda a determinar a viabilidade da cultura celular. Três tipos com diferentes capacidades de multiplicação já foram identificados. O holoclone tem alta capacidade proliferativa e é considerado como uma colônia de células tronco epidérmicas ${ }^{(28)}$. O paraclone é formado pelas células amplificadoras transitórias com capacidade máxima de 15 divisões celulares e formam colônias contendo somente células terminalmente diferenciadas ${ }^{(28)}$. O meroclone é um tipo intermediário de clone e é um reservatório de células amplificadoras transitórias ${ }^{(29)}$. A transição de holoclone para meroclone e paraclone é um processo unidirecional que ocorre naturalmente durante a idade, bem como durante cultivo celular seriado. Em cultura, holoclones tem o maior potencial de crescimento por serem compostos por células especializadas mais indiferenciadas, com capacidade de proliferarem, expandirem e formarem uma cultura epitelial com possibilidade de uso terapêutico.

Neste estudo foi realizada cultura de células epiteliais do limbo pela suspensão de células obtidas de rimas córneoesclerais com e sem fibroblastos 3T3 irradiados como substrato. Pudemos observar que as células epiteliais do limbo quando cultivadas sobre $3 \mathrm{~T} 3$ formaram colônias epiteliais com características de holo ou meroclones, que ficaram aderidas às placas de cultura após a fixação e coloração com rodamina $\mathrm{B}$. Por outro lado, nenhuma adesão ou formação de clones verdadeiros foi observada na cultura de células quando cultivadas sem fibroblastos 3T3. Esses achados corroboram as hipóteses que: 1) as culturas obtidas pela suspensão de células que foram enzimaticamente isoladas do tecido contêm células tronco com capacidade para formarem clones de células epiteliais; 2) há a necessidade de se utilizar, nesse sistema, co-cultivo com camada nutriente de fibroblastos 3T3 para que ocorra preservação e expansão das células progenitoras na forma de colônias (holo ou meroclones).

Além disso, foram realizadas culturas primárias de células epiteliais do limbo obtidas a partir de explantes de rimas córneo-esclerais, colocados diretamente sobre as placas de cultura. Esse modelo, por nós já utilizado com sucesso em outros experimentos, serviu como controle positivo. O fato de em dois casos não termos observado crescimento pode ser explicado pelas variações intra-amostrais desse tipo de sistema e por características do doador, principalmente o tempo entre a morte e preservação do tecido e preservação e cultura, que foram maiores nesses dois casos. Interessante o fato de terem afetado de modo mais intenso o grupo A (cultivo a partir do explante colocado na placa) do que o grupo B (suspensão de células + fibroblastos 3T3). Talvez o co-cultivo com camada nutriente tenha conseguido reverter o processo de dano celular e mantido as propriedades das células progenitoras límbicas presentes nessas culturas.

\section{CONCLUSÃO}

Nossos resultados mostraram que células epiteliais do limbo obtidas de rimas de cadáveres foram capazes de proliferar e formar colônias celulares in vitro. Essas células, quando tripsinizadas e co-cultivadas com fibroblastos $3 \mathrm{~T} 3$ irradiados no meio SHEM, mantiveram as características de células epiteliais progenitoras do limbo formando clones (holo e meroclones). Esses achados sugerem que este sistema de cultura pode ser útil para o estudo dos mecanismos fisiológicos 
das células progenitoras do epitélio corneal e para a aplicação terapêutica em casos de deficiência total das células tronco epiteliais límbicas.

\section{ABSTRACT}

Purpose: To evaluate the importance of the presence of 3T3 fibroblasts for establishing limbal epithelial cultures from cell suspension obtained from corneo-scleral rims (CSR). Methods: Corneo-scleral rims from different donors $(n=6)$ had their posterior stroma and endothelium stripped away. Each corneo-scleral rim was divided into three equal segments that were set up in tissue culture in three different conditions: one of the segments was placed with the epithelial side up on the bottom of a 6-well culture plate (Group A). The other two fragments were trypsinized and the obtained cell suspension was cultured with (Group B) or without (Group C) irradiaded 3T3 cells. The cells were cultured in supplemental hormonal epithelial medium (SHEM), the epithelial migration and clone formation in groups $\mathrm{A}, \mathrm{B}$ and $\mathrm{C}$ were evaluated with phase contrast microscopy and rodamine B staining. Results: Epithelial cell growth was observed in 4/6 rims (Group A). All epithelial cell suspensions that were cultured with 3T3 cells (Group B) formed clones. No adhesion or true clone formation (holo- or meroclones) was observed in the cell suspensions that were cultivated without 3T3 (Group C) $(\mathrm{p}=0.009)$. Conclusions: Epithelial cell suspension obtained from corneo-scleral rims in this model needs to be cultivated with $3 \mathrm{~T} 3$ cells in order to form clones and establish limbal epithelial cell colonies with the potential to be used for ocular surface reconstruction.

Keywords: Epithelial cells; Cell culture techniques; Cell differentiation; Stem cells; Limbus corneae

\section{REFERÊNCIAS}

1. Tsai RJ, Sun TT, Tseng SC. Comparison of limbal and conjunctival autograft transplantation in corneal surface reconstruction in rabbits. Ophthalmology. 1990;97(4):446-55.

2. Wei ZG, Sun TT, Lavker RM. Rabbit conjunctival and corneal epithelial cells belong to two separate lineages. Invest Ophthalmol Vis Sci. 1996;37(4):523-33.

3. Wei ZG, Wu RL, Lavker RM, Sun TT. In vitro growth and differentiation of rabbit bulbar, fornix, and palpebral conjunctival epithelium. Implications on conjunctival epithelial transdifferentiation and stem cells. Invest Ophthalmol Vis Sci. 1993;34(5):1814-28.

4. Chen WY, Mui MM, Kao WW, Liu CY, Tseng SC. Conjunctival epithelial cells do not transdifferentiate in organotypic cultures: expression of K12 keratin is restricted to corneal epithelium. Curr Eye Res. 1994;13(10):765-78

5. Schermer A, Galvin S, Sun TT. Differentiation-related expression of a major $64 \mathrm{~K}$ corneal keratin in vivo and in culture suggests limbal location of corneal epithelial stem cells. J Cell Biol. 1986;103(1):49-62.

6. Tsubota K, Toda I, Saito H, Shinozaki N, Shimazaki J. Reconstruction of the corneal epithelium by limbal allograft transplantation for severe ocular surface disorders. Ophthalmology. 1995;102(10):1486-96.

7. Pellegrini G, Traverso CE, Franzi AT, Zingirian M, Cancedda R, De Luca M. Long-term restoration of damaged corneal surfaces with autologous cultivated corneal epithelium. Lancet. 1997;349(9057):990-3. Comment in: Lancet. 1997;349(9064):1556.

8. He YG, Alizadeh H, Kinoshita K, McCulley JP. Experimental transplantation of cultured human limbal and amniotic epithelial cells onto the corneal surface. Cornea. 1999;18(5):570-9.

9. Kruse FE, Tseng SC. Growth factors modulate clonal growth and differentiation of cultured rabbit limbal and corneal epithelium. Invest Ophthalmol Vis Sci. 1993;34(6):1963-76.

10. de Melo GB, Gomes JA, da Gloria MA, Martins MC, Haapalainen EF. [Morphological assessment of different amniotic membrane epithelial denuding techniques]. Arq Bras Oftalmol. 2007;70(3):407-11. Portuguese.

11. Ye ZQ, Burkholder JK, Qiu P, Schultz JC, Shahidi NT, Yang NS. Establishment of an adherent cell feeder layer from human umbilical cord blood for support of long-term hematopoietic progenitor cell growth. Proc Natl Acad Sci USA. 1994;91(25):12140-4.

12. Fujiyama C, Masaki Z, Sugihara H. Reconstruction of the urinary bladder mucosa in three-dimensional collagen gel culture: fibroblast-extracellular matrix interactions on the differentiation of transitional epithelial cells. J Urol. 1995;153(6):2060-7.

13. Tanioka H, Kawasaki S, Yamasaki K, Ang LP, Koizumi N, Nakamura T, et al. Establishment of a cultivated human conjunctival epithelium as an alternative tissue source for autologous corneal epithelial transplantation. Invest Ophthalmol Vis Sci. 2006;47(9):3820-7.

14. Nishida K, Yamato M, Hayashida Y, Watanabe K, Yamamoto K, Adachi E, et al. Corneal reconstruction with tissue-engineered cell sheets composed of autologous oral mucosal epithelium. N Engl J Med. 2004;351(12):1187-96. Comment in: N Engl J Med. 2004;351(12):1170-2.

16. Gomes JA, Rizzo LV, Nishi M, Donoso LA, Dua HS. Influência do epitélio corneal limbar sobre a expressão do antígeno dos linfócitos da mucosa humana (HML-1). Arq Bras Oftalmol. 1997;60(6):588-97.

17. Coligan JE, Kruisbeek AM, Margulies DH, Shevach EM, Strober W. Trypan blue exclusion test of cell viability. In: Coligan JE, Kruisbeek AM, Margulies DH, Shevach EM, Strober W, editors. Current protocols in immunology. New York: Wiley \& Sons; 1990. p. A.3.3.

18. Phillips HJ. Dye exclusion tests for cell viability. In: Kruse Jr PF, Patterson Jr MK, editors. Tissue culture: methods and applications. New York: Academic Press; 1973: p. 406-8.

19. Schofield R. The stem cell system. Biomed Pharmacother. 1983;37(8):375-80.

20. Tseng SC. Regulation and clinical implications of corneal epithelial stem cells. Mol Biol Rep. 1996;23(1):47-58.

21. Morrison SJ, Shah NM, Anderson DJ. Regulatory mechanisms in stem cell biology. Cell. 1997;88(3):287-98.

22. Watt FM, Hogan BL. Out of Eden: stem cells and their niches. Science. 2000;287(5457):1427-30.

23. Espana EM, Kawakita T, Romano A, Di Pascuale M, Smiddy R, Liu CY, et al. Stromal niche controls the plasticity of limbal and corneal epithelial differentiation in a rabbit model of recombined tissue. Invest Ophthalmol Vis Sci. 2003;44(12):5130-5.

24. Grueterich M, Espana EM, Tseng SC. Ex vivo expansion of limbal epithelial stem cells: amniotic membrane serving as a stem cell niche. Surv Ophthalmol. 2003;48(6):631-46.

25. Alitalo K, Kuismanen E, Myllyla R, Kiistala U, Asko-Seljavaara S, Vaheri A. Extracellular matrix proteins of human epidermal keratinocytes and feeder 3T3 cells. J Cell Biol. 1982;94(3):497-505.

26. Green H. Cyclic AMP in relation to proliferation of the epidermal cell: a new view. Cell. 1978;15(3):801-11.

27.Gospodarowicz D, Delgado D, Vlodavsky I. Permissive effect of the extracellular matrix on cell proliferation in vitro. Proc Natl Acad Sci USA. 1980;77(7):4094-8.

28. Barrandon Y, Green H. Three clonal types of keratinocyte with different capacities for multiplication. Proc Natl Acad Sci USA. 1987;84(8):2302-6.

29. Schermer A, Galvin S, Sun TT. Differentiation-related expression of a major $64 \mathrm{~K}$ corneal keratin in vivo and in culture suggests limbal location of corneal epithelial stem cells. J Cell Biol. 1986;103(1):49-62. 